Check for updates

Cite this: RSC Adv., 2017, 7, 42138

Received 2nd July 2017

Accepted 25th August 2017

DOI: 10.1039/c7ra07289a

rsc.li/rsc-advances

\section{SERS as a probe for the charge-transfer process in a coupled semiconductor nanoparticle system $\mathrm{TiO}_{2} / \mathrm{MBA} / \mathrm{PbS} \uparrow$}

\begin{abstract}
Xiaolei Zhang, ${ }^{\mathrm{ab}}$ Lin Guo, ${ }^{a}$ Peng $\mathrm{Li}^{,}{ }^{\mathrm{a}}$ Bing Zhao ${ }^{\mathrm{D}}{ }^{\text {*a }}$ and Bo Cui ${ }^{\mathrm{b}}$
A coupled semiconductor nanoparticle system composed of $\mathrm{TiO}_{2} \mathrm{NPs}$, 4-mercaptobenzoic acid (4-MBA) molecules and PbS NPs has been fabricated as a model to study the involved charge transfer (CT) effect using a Surface-Enhanced Raman Scattering (SERS) technique. In this $\mathrm{TiO}_{2} / \mathrm{MBA} / \mathrm{PbS}$ system, the MBA molecules function as both a linker between $\mathrm{TiO}_{2}$ and PbS NPs and a SERS probe to reveal the CT process. For the SERS enhancement behaviors of the CT-sensitive vibrational mode in 4-MBA and the Raman spectra of the phonon vibrational mode in $\mathrm{TiO}_{2} \mathrm{NPS}$, there are some evident changes after adding $\mathrm{PbS}$ to the $\mathrm{TiO}_{2} / \mathrm{MBA}$ system. These changes are due to the interaction between $\mathrm{TiO}_{2} \mathrm{NPs}$ and $\mathrm{PbS}$ NPs. We found that these differences, closely related to the natures of $\mathrm{TiO}_{2}$ and PbS NPs, are a reflection of the enhanced $\mathrm{TiO}_{2}$-to-molecule CT process in SERS. The SERS spectra of the $\mathrm{TiO}_{2} / \mathrm{MBA} /$ CdS system were also investigated and the result is in good accordance with our theory. This work will not only help in constructing nanoscale models to study interfacial CT processes but also be of considerable value for practical application of SERS technology.
\end{abstract}

\section{Introduction}

Coupled semiconductor nanoparticle systems have been the subject of numerous investigations in recent years; the origin of the extensive interest is that coupled semiconductor nanoparticle systems exhibit a wide range of novel photoelectric properties that are finding application in solar cells, photocatalysis, supercapacitors and other power conversation devices. However, for many coupled semiconductor nanoparticle systems, the understanding of the interparticle CT processes between different semiconductor particles are still unclear, which is vital for both photoelectric efficiencies of various electronic devices and photocatalytic efficiency of different catalytic reactions.

To develop practical devices based on these coupled semiconductor nanoparticle systems, many efforts have been made to explore the possible CT process involved. Bessekhouad et al. ${ }^{1}$ prepared $\mathrm{CdS} / \mathrm{TiO}_{2}$ and $\mathrm{Bi}_{2} \mathrm{~S}_{3} / \mathrm{TiO}_{2}$ heterojunctions with direct mixture and precipitation methods and analyzed the CT mechanism in the photocatalytic degradation of organic pollutants. Im et al. ${ }^{2}$ used the bi-semiconductors of $\mathrm{TiO}_{2}$ and

\footnotetext{
${ }^{a}$ State Key Laboratory of Supramolecular Structure and Materials, Jilin University, Changchun 130012, P. R. China. E-mail: zhaob@mail.jlu.edu.cn; Fax: +86-43185193421; Tel: $+86-431-85168473$

${ }^{b}$ Department of Electrical and Computer Engineering, Waterloo Institute for Nanotechnology (WIN), University of Waterloo, Waterloo, Ontario N2L 3G1, Canada $\dagger$ Electronic supplementary information (ESI) available. See DOI: $10.1039 / \mathrm{c} 7 \mathrm{ra} 07289 \mathrm{a}$
}

$\mathrm{Fe}_{2} \mathrm{O}_{3}$ as a photoelectrode material in a high performance dyesensitized solar cell and discussed the mechanism whereby the conduction band of $\mathrm{Fe}_{2} \mathrm{O}_{3}$ works to prohibit the trapping effects of electrons in the conduction band of $\mathrm{TiO}_{2}$. Ghadiri et al. ${ }^{3}$ reported on the kinetics of the interfacial charge separation of $\mathrm{PbS}$ QDs/(001) $\mathrm{TiO}_{2}$ nanosheets heterojunction solar cells. Additionally, $\mathrm{MoS}_{2} / \mathrm{TiO}_{2},{ }^{4} \mathrm{ZnO} / \mathrm{TiO}_{2},{ }^{5}$ and $\mathrm{ZnO} / \mathrm{PbS},{ }^{6}$ heterojunctions were also investigated to study the charge-transfer processes in different applications. However, a research gap remains to be filled in order to reveal the CT processes in coupled semiconductor nanoparticle systems more intuitively, which calls for more suitable experimental techniques.

Since it was discovered on a rough silver electrode in $1974,{ }^{7}$ the surface-enhanced Raman scattering (SERS) has seen renewed interest over the past decades because of its high sensitivity, high selectivity, and nondestructive nature. Today SERS is being widely applied to many areas, such as analytical chemistry, ${ }^{8-10}$ electrochemistry, ${ }^{11}$ life science, ${ }^{12-14}$ material area ${ }^{15,16}$ and environment monitoring. ${ }^{17}$ There are two primary mechanisms that account for SERS: electromagnetic mechanism (EM) and chemical enhancement mechanism (CM). ${ }^{18,19}$ EM requires the coupling of metallic nanoparticles and incident radiation, ${ }^{20}$ whereas $\mathrm{CM}$ involves a CT process between the substrate and adsorbate. ${ }^{21,22}$ Typically, chemical enhancement is a resonance Raman-like process, which is sensitive to polarizability change of probe molecules. For most semiconductor materials, the surface plasmon resonant frequency is located in the infrared region. Thus, when semiconductor materials are applied as SERS substrates, the $\mathrm{CM}$ can be the dominant 
contribution to the surface-enhanced Raman signal on the semiconductor substrates, which provides an extensive space for studying CT processes in coupled semiconductor nanoparticle systems. That is to say, under the function of the chemical enhancement mechanism, the CT process in a definite system can be reflected in the corresponding SERS spectra by changing the polarizability of the adsorbed molecules. Therefore, one can study nanoscale interfacial CT processes in coupled semiconductor nanoparticle systems with the help of appropriate SERS CT models.

In this work, we fabricated an ordered coupled semiconductor nanoparticle system composed of $\mathrm{TiO}_{2} \mathrm{NPs}$, probe molecules and PbS NPs as a SERS model to study the involved interfacial CT effects. The development of the semiconductorcoupled SERS model $\mathrm{TiO}_{2} / \mathrm{MBA} / \mathrm{PbS}$ was based on electrostatic interactions described in the literature with only slight modification. ${ }^{23}$ First, the $\mathrm{TiO}_{2}$ surfaces were first treated with MBA molecules where the $-\mathrm{SH}$ provides a binding site for $\mathrm{Pb}^{2+}$ ions. Then by reacting $\mathrm{Na}_{2} \mathrm{~S}$ with the $\mathrm{Pb}^{2+}$ ions, the $\mathrm{PbS}$ NPs were made onto the $\mathrm{TiO}_{2}$ surfaces absorbed on the pretreated surfaces. Different from the method described previously, we replace the molecule mercaptopropionic acid (MPA) with MBA which functions as both a linker in coupled and a SERS probe to reveal how charge transits in our system. For MBA molecules, the carboxyl group and mercapto group can bind strongly to $\mathrm{TiO}_{2}$ NPs and PbS NPs, respectively. ${ }^{23,24}$ Thus, the order of this semiconductor-molecule-semiconductor CT system is fixed, which provides a high order for investigating the CT process. In this paper, the possible CT process involved in $\mathrm{TiO}_{2} / \mathrm{MBA} / \mathrm{PbS}$ is discussed to develop the theory behind interfacial CT effects between semiconductors. The present work is conducive to further investigation of the interfacial CT process in coupled semiconductor nanoparticle system with the SERS technique.

\section{Experimental}

\section{Chemicals}

4-Mercaptobenzoic acid (MBA) and titanium(Iv) butoxide were purchased from Sigma-Aldrich and used without further purification. The other regents (lead nitrate, anhydrous ethanol, nitric acid, sodium sulfide) were all analytical grade. The distilled and deionized water from a Milli-Q-plus system with the resistivity $>18.0 \mathrm{M} \Omega$ was used in aqueous solution.

\section{Synthesis of $\mathrm{TiO}_{2}$ NPs}

In this work, the synthesis of $\mathrm{TiO}_{2}$ NPs is mainly based on a solhydrothermal process described in previous literature. ${ }^{22}$ First, a mixed solution of $5 \mathrm{~mL}$ of titanium(Iv) butoxide and $5 \mathrm{~mL}$ of anhydrous ethanol was added dropwise into another mixed solution, consisting of $20 \mathrm{~mL}$ of anhydrous ethanol, $5 \mathrm{~mL}$ of deionized water, and $1 \mathrm{~mL}$ of $70 \%$ nitric acid, under rough stirring at room temperature. With the hydrolysis of titanium(Iv) butoxide, a light yellow transparent sol was obtained by continuously stirring for $2 \mathrm{~h}$. Then, the as-prepared sol was kept at $160{ }^{\circ} \mathrm{C}$ for $6 \mathrm{~h}$ in a stainless-steel vessel. After cooled to room temperature, the pasty production was washed with water and dried at $60{ }^{\circ} \mathrm{C}$ for $24 \mathrm{~h}$. Finally, $\mathrm{TiO}_{2}$ NPs were obtained by calcining the dried product at $450{ }^{\circ} \mathrm{C}$ for $2 \mathrm{~h}$.

\section{Preparation of $\mathrm{TiO}_{2} / \mathrm{MBA}$ system}

The $\mathrm{TiO}_{2} / \mathrm{MBA}$ system was prepared following the steps below. In brief, $20 \mathrm{mg}$ of the prepared $\mathrm{TiO}_{2}$ NPs was soaked in the MBA/ ethanol solution $\left(10^{-3} \mathrm{M}\right)$ and the mixture was stirred for $6 \mathrm{~h}$. Subsequently, the precipitate was centrifuged and rinsed with anhydrous ethanol once more. After drying, the $\mathrm{TiO}_{2} / \mathrm{MBA}$ system was obtained.

\section{Preparation of $\mathrm{TiO}_{2} / \mathrm{MBA} / \mathrm{PbS}$ system}

The $\mathrm{TiO}_{2} / \mathrm{MBA} / \mathrm{PbS}$ system was prepared based on electrostatic interactions previously described in the literature with only slight modifications. ${ }^{23,24} \mathrm{~A} 2 \mathrm{mM} \mathrm{Pb}\left(\mathrm{NO}_{3}\right)_{2}$ aqueous solution was added into the prepared $\mathrm{TiO}_{2} / \mathrm{MBA}$ system to allow $\mathrm{Pb}^{2+}$ ions to absorb on the $\mathrm{TiO}_{2} \mathrm{NP}$ surfaces under stirring. To crystallize the $\mathrm{PbS}$ NPs onto the $\mathrm{TiO}_{2}$, a $5 \mathrm{mM} \mathrm{Na}_{2} \mathrm{~S}$ aqueous solution was added. Then the pasty production was separated by centrifuge and washed with water. After drying at $60{ }^{\circ} \mathrm{C}$ for $24 \mathrm{~h}$, we obtained the $\mathrm{TiO}_{2} / \mathrm{MBA} / \mathrm{PbS}$ system. The fabrication process of $\mathrm{TiO}_{2} / \mathrm{MBA} / \mathrm{PbS}$ system is presented in Fig. 1.

\section{Preparation of $\mathrm{TiO}_{2} / \mathrm{MBA} / \mathrm{CdS}$ system}

In order to preparing $\mathrm{TiO}_{2} / \mathrm{MBA} / \mathrm{CdS}$ system, we take advantage of the electrostatic interactions between nanoparticles and ions as previously described in the literature with only slight modifications. ${ }^{25}$ A $2 \mathrm{mM} \mathrm{Cd}(\mathrm{Ac})_{2} \cdot 2 \mathrm{H}_{2} \mathrm{O}$ ethanol solution was then added into the prepared $\mathrm{TiO}_{2} / \mathrm{MBA}$ system to allow $\mathrm{Cd}^{2+}$ ions to absorb on the $\mathrm{TiO}_{2} \mathrm{NP}$ surfaces under stirring. To crystallize the CdS NPs onto the $\mathrm{TiO}_{2}$ NPs, $6 \mathrm{mM}$ thiourea was slowly added dropwise into the solution under vigorous stirring. Thereafter, the $\mathrm{pH}$ was adjusted to 10 with $0.2 \mathrm{M} \mathrm{NaOH}$ solution. Then the reaction was kept for an additional $12 \mathrm{~h}$ at room temperature. The resulting composite particles were washed with distilled water. After drying, the $\mathrm{TiO}_{2} / \mathrm{MBA} / \mathrm{CdS}$ system was obtained.

\section{Instrumentation}

TEM images were taken using a Jeol JEM 2100F transmission electron microscope operating at $200 \mathrm{kV}$. The crystal structure

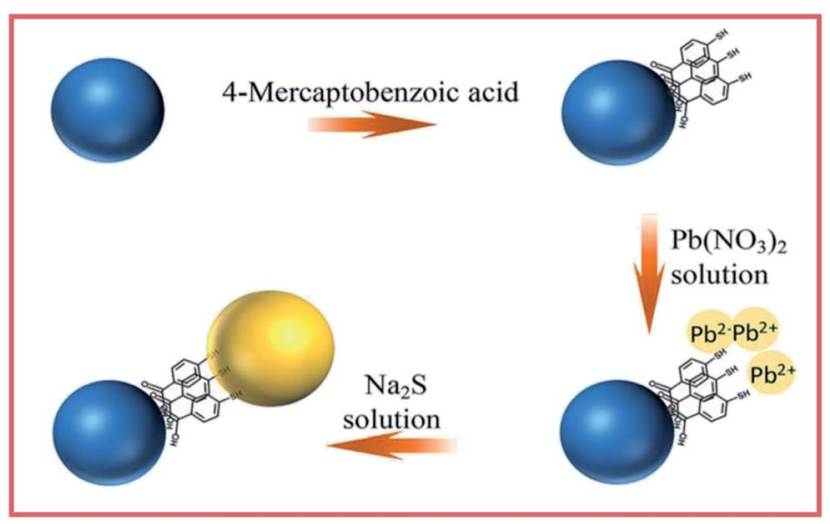

Fig. 1 The fabrication process of $\mathrm{TiO}_{2} / \mathrm{MBA} / \mathrm{PbS}$ system. 
of samples was determined by X-ray diffraction (XRD) using a Siemens D5005 X-ray powder diffractometer with a $\mathrm{Cu} \mathrm{K} \alpha$ radiation source at $40 \mathrm{kV}$ and $30 \mathrm{~mA}$. The ultraviolet-visible (UVvis) diffuse reflectance spectra (UV-vis DRS) were recorded on a Lambda UV-950 UV-vis spectrometer. Raman spectra were obtained using a Horiba-Jobin Yvon LabRAM ARAMIS system. The $633 \mathrm{~nm}$ radiation from a $20 \mathrm{~mW}$ air-cooled HeNe narrow bandwidth laser was used as an exciting source. Data was acquired with the $10 \mathrm{~s}$ accumulations for MBA molecules in the different systems at ambient temperature. Meanwhile, to avoid the photodegradation effect, all the samples were tested with at a low laser power of $0.27 \mathrm{~mW}$ (monitored by filter D1).

\section{Results and discussion}

\section{Characterization of morphology and crystal structure of different systems}

Fig. 2a and b shows the TEM image and the X-ray diffraction (XRD) pattern of the $\mathrm{TiO}_{2}$ NPs after hydrothermal processing and calcination. It can be seen from Fig. 2a that the $\mathrm{TiO}_{2} \mathrm{NPs}$ are all irregular sphere-like particles with a diameter of about $10 \mathrm{~nm}$. According to JPCDS 21-1272, the observed lattice spacing of $0.351 \mathrm{~nm}$ in Fig. 2a corresponds to the (101) plane of anatase $\mathrm{TiO}_{2}$. Fig. 2b shows the XRD pattern of $\mathrm{TiO}_{2}$ NPs calcined at $450{ }^{\circ} \mathrm{C}$. In general, the XRD peak at $2 \theta=25.3^{\circ}$ is identified as the characteristic diffraction peak of the anatase phase of $\mathrm{TiO}_{2}{ }^{26}$

Fig. 2b reveals that the $\mathrm{TiO}_{2} \mathrm{NPs}$ calcined at $450{ }^{\circ} \mathrm{C}$ were monolithic anatase phase $\mathrm{TiO}_{2}$, which also agrees well with the reported data in JPCDS 21-1272. Estimated from the halfbandwidth $(\beta)$ of the corresponding X-ray spectral peak by the Scherrer formula: $D=k \lambda /(\beta \cos \theta),{ }^{27}$ the crystalline size $D$ was about $9.1 \mathrm{~nm}$, which is consistent with the size value obtained from the TEM image.

Fig. $2 \mathrm{c}$ and $\mathrm{d}$ presents the TEM image and the XRD patterns of the $\mathrm{TiO}_{2} / \mathrm{MBA} / \mathrm{PbS}$ system. Inspection of the Fig. 2c TEM image reveals that $\mathrm{PbS}$ NPs, with an average diameter of about $70 \mathrm{~nm}$, are surrounded by $\mathrm{TiO}_{2}$ NPs. The crystallinity of PbS NPs can clearly be seen, where the distance of the crystalline plane was measured to be $0.342 \mathrm{~nm}$, indicating a (111) plane of cubic $\mathrm{PbS}$ (JPCDS 05-0592). Fig. 2d shows the XRD pattern of the $\mathrm{TiO}_{2} /$ MBA/PbS system. The presence of PbS (black line, JPCD05-0592) and $\mathrm{TiO}_{2}$ (red line, JPCDS 21-1272) diffraction peaks can be observed clearly in Fig. 2d. Both the TEM image and the XRD pattern provide clear evidence of the successful fabrication of the $\mathrm{TiO}_{2} / \mathrm{MBA} / \mathrm{PbS}$ system.

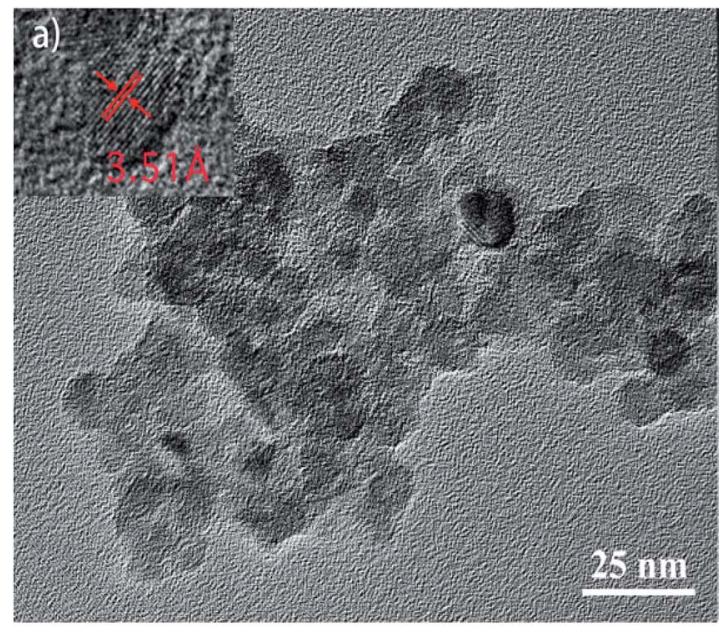

\section{c)}
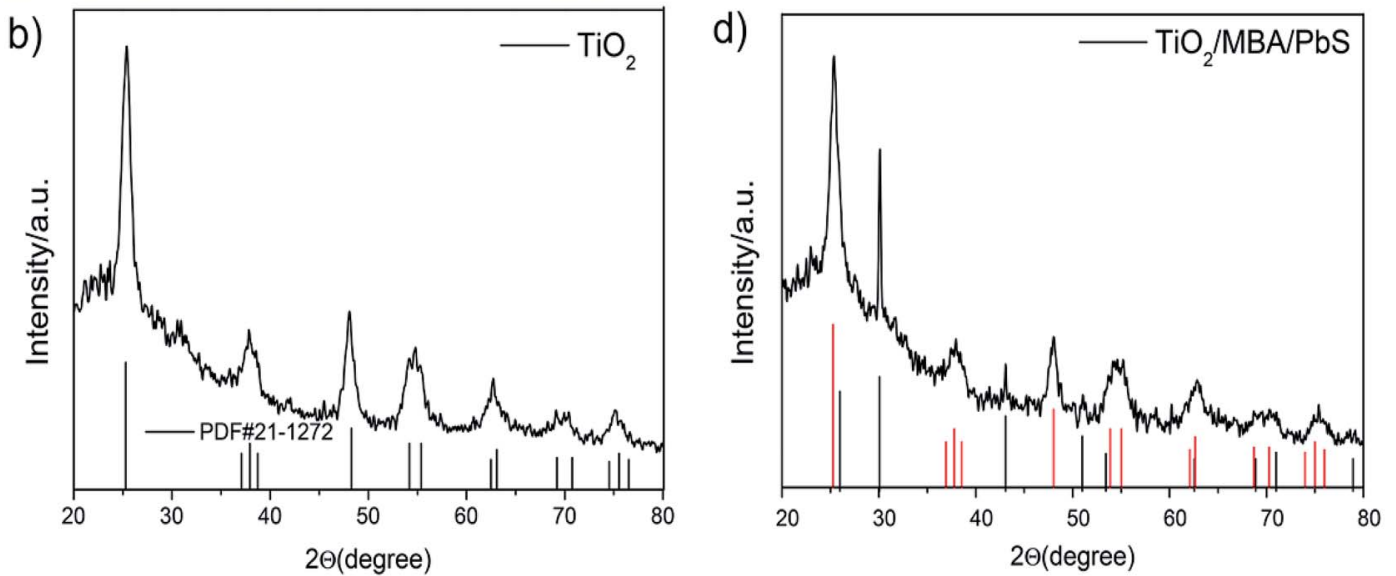

Fig. 2 The TEM image and the XRD patterns of the pure $\mathrm{TiO}_{2} \mathrm{NPs}\left(\mathrm{a}\right.$ and $\mathrm{b}$ ) and $\mathrm{TiO}_{2} / \mathrm{MBA} / \mathrm{PbS}$ system (c and d). In (c), the particles inside red circle are $\mathrm{TiO}_{2}$ NPs. 


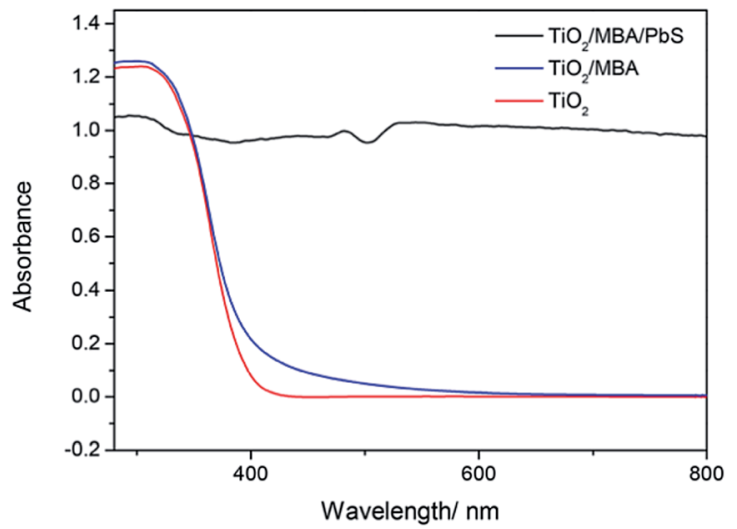

Fig. 3 The UV-visible absorption spectra have obtained to characterize the photoelectric property of different systems.

\section{Measurement of UV-vis spectra}

The UV-visible absorption spectra have obtained to characterize the photoelectric property of different systems. Fig. 3 shows the UV-vis absorption spectra of $\mathrm{TiO}_{2}, \mathrm{TiO}_{2} / \mathrm{MBA}$ and $\mathrm{TiO}_{2} / \mathrm{MBA} / \mathrm{PbS}$ systems. Pure $\mathrm{TiO}_{2}$ shows a band-edge absorption around $395 \mathrm{~nm}$ (3.14 eV), which is close to the reported value. ${ }^{28}$ After modification by MBA molecules, the photoabsorption threshold of $\mathrm{TiO}_{2}$ exhibits a slight shift, which can be ascribed to the influence of the molecules adsorbed on $\mathrm{TiO}_{2}$ NPs. Similar phenomena have been observed in previous literatures..$^{22,29,30}$ Moreover, its photoresponse is extended to about $600 \mathrm{~nm}$. These changes can be attributed to a new charge-transfer (CT) complex formed between the adsorbed molecules and the $\mathrm{TiO}_{2}$ substrate. After introducing PbS NPs, the system shows a strong absorption of visible light because of PbS NPs presence. By comparison, we also synthesize cubic PbS NPs with similar diameter of about $70 \mathrm{~nm}$ (Fig. S1†). Fig. S2 $\uparrow$ shows the UV-vis absorption spectra of PbS NPs with strong absorption between 200-800 nm. Thus, it can be concluded that the $\mathrm{TiO}_{2} / \mathrm{MBA} / \mathrm{PbS}$ coupled semiconductor nanoparticle system is fabricated.

\section{SERS spectra of different semiconductor systems}

SERS spectra (excited at $633 \mathrm{~nm}$ ) of MBA molecules in the $\mathrm{TiO}_{2} /$ MBA and $\mathrm{TiO}_{2} / \mathrm{MBA} / \mathrm{PbS}$ systems are shown in Fig. 4a.

To avoid the photodegradation effect of laser, all the samples were tested at a low laser power of $0.27 \mathrm{~mW}$ (monitored by filter D1). ${ }^{31}$ The Raman shifts and assignments of the bands are listed in Table 1.

For MBA molecules in the $\mathrm{TiO}_{2} / \mathrm{MBA}$ system (black line, Fig. 4a), one of the predominant bands is located at $1075 \mathrm{~cm}^{-1}$, which has been assigned to the in-plane ring breathing mode coupled with $\nu(\mathrm{C}-\mathrm{S})$. Another predominant band is an overlap result of two SERS bands: the aromatic $\nu$ (CC) mode (at $1592 \mathrm{~cm}^{-1}$ ) and the non-totally symmetric stretching mode (at $\left.1583 \mathrm{~cm}^{-1}\right) .^{32,33}$ Two weak bands at about $1147(\nu 15, \mathrm{~b} 2)$ and $1181 \mathrm{~cm}^{-1}(\nu 9$, a1) can also be observed and are attributed to the $\mathrm{C}-\mathrm{H}$ deformation mode. These two weak bands are characteristic SERS signals of the 4-MBA molecule on the $\mathrm{TiO}_{2}$ substrates and consistent with those previously reported in $\mathrm{TiO}_{2} / 4-\mathrm{MBA}$
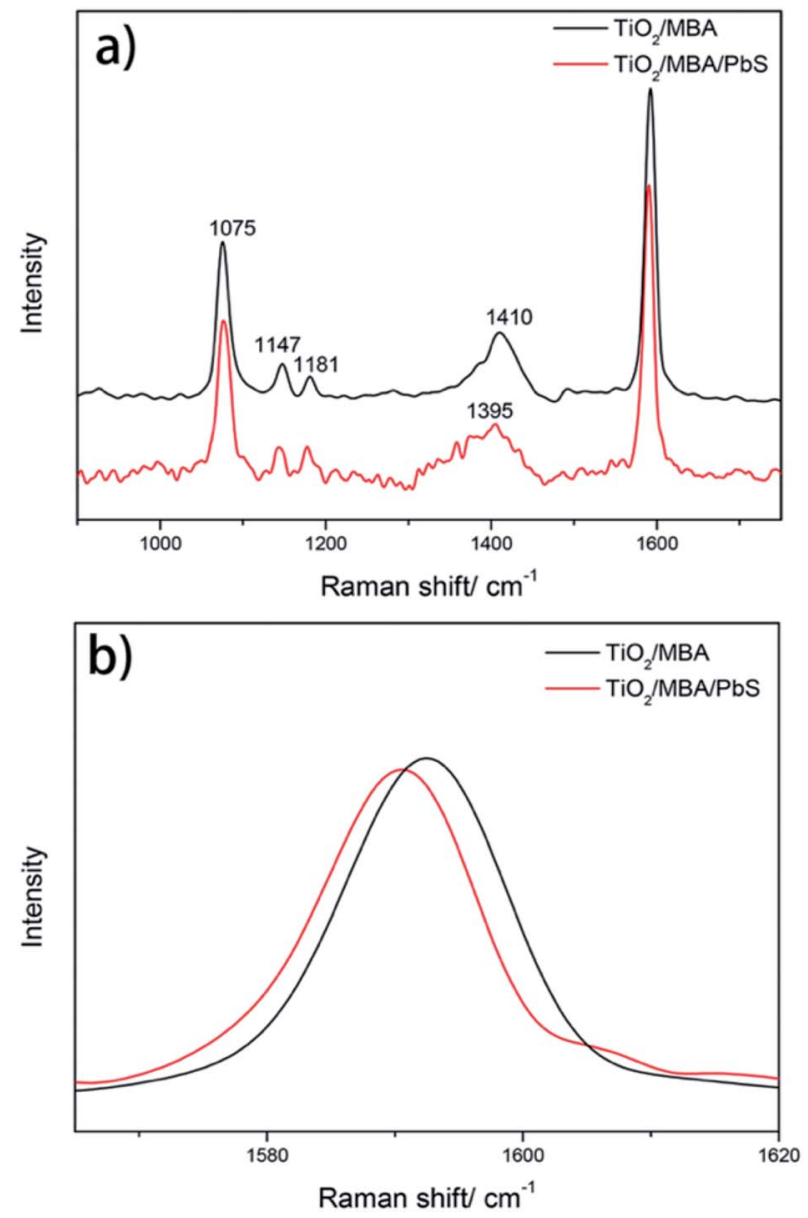

Fig. 4 (a) The SERS spectra of $\mathrm{TiO}_{2} / \mathrm{MBA}$ and $\mathrm{TiO}_{2} / \mathrm{MBA} / \mathrm{PbS}$ systems at $633 \mathrm{~nm}$ excitation and (b) the enlarged SERS spectra between 1565 and $1620 \mathrm{~cm}^{-1}$.

systems. In previous works, ${ }^{30,34}$ the SERS signals in the $\mathrm{TiO}_{2} /$ MBA system have been attributed to the dominant contribution of the $\mathrm{TiO}_{2}$-to-molecule CT mechanism. After introducing $\mathrm{PbS}$ NPs into the $\mathrm{TiO}_{2} / \mathrm{MBA}$ system (black line, Fig. 4a), some changes in the SERS bands were observed. For comparison, the Raman spectra were normalized using the band at $1075 \mathrm{~cm}^{-1}$. For clarity, the magnified SERS spectra of 4-MBA molecules

Table 1 Wavenumbers and assignments of bands in the SERS spectrum of MBA molecular ${ }^{a}$

Wavenumbers

$\left(\mathrm{cm}^{-1}\right) \quad$ Band assignments

1075

1147

1181

1411

1583

1592

${ }^{a} \nu$, stretching; $\beta$, bending. For ring vibrations, the corresponding vibrational modes of benzene and the symmetry species with $C_{2 \mathrm{v}}$ symmetry are indicated. 

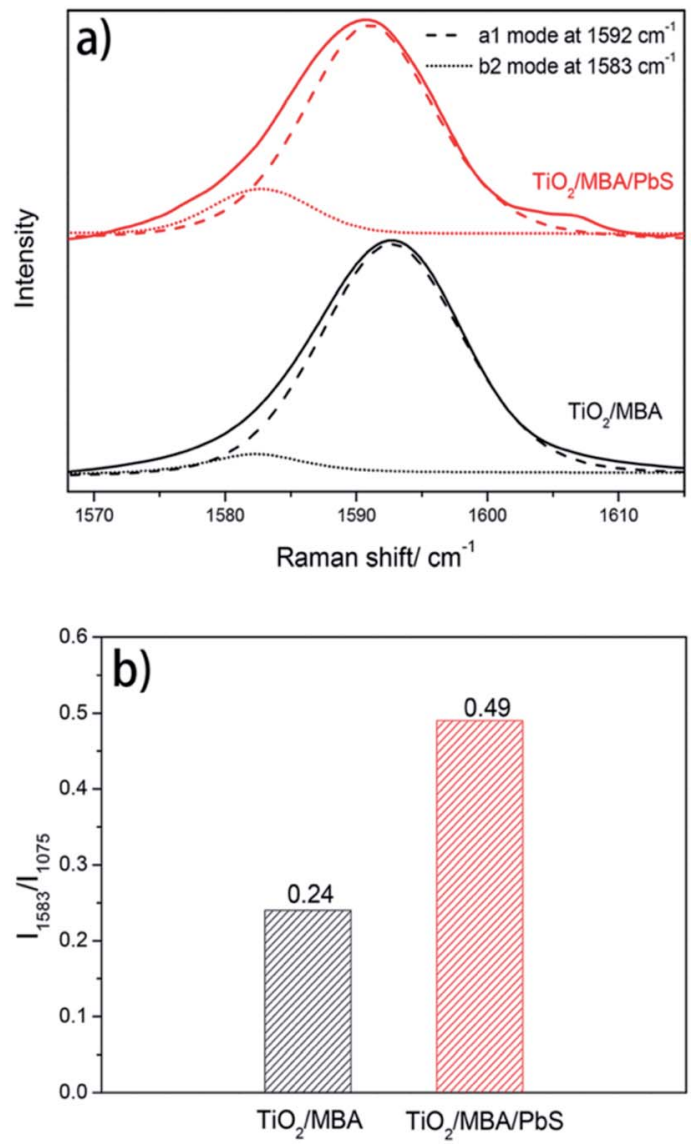

Fig. 5 (a) The nonlinear Lorentzian fit curve of the SERS spectra in the $\mathrm{TiO}_{2} / \mathrm{MBA}$ and $\mathrm{TiO}_{2} / \mathrm{MBA} / \mathrm{PbS}$ systems between 1568 and $1615 \mathrm{~cm}^{-1}$; (b) the SERS intensity ratio between the modes at 1583 and $1075 \mathrm{~cm}^{-1}$ spectra in the $\mathrm{TiO}_{2} / \mathrm{MBA}$ and $\mathrm{TiO}_{2} / \mathrm{MBA} / \mathrm{PbS}$ systems.

between 1565 and $1620 \mathrm{~cm}^{-1}$ are shown in Fig. 4b. The band at $1583 \mathrm{~cm}^{-1}$ assigned to non-totally symmetric $\nu$ (CC) displays an increase in the intensity of the SERS spectrum after introducing $\mathrm{PbS}$ NPs, while band at $1592 \mathrm{~cm}^{-1}$ assigned to the aromatic $\nu$ (CC) mode has no distinct changes. Meanwhile, it is worth noting that the peak at $1410 \mathrm{~cm}^{-1}$ (Fig. 4a) is broadened and shifts after the introduction of PbS NPs, which provides more evidence that MBA molecules bind to $\mathrm{TiO}_{2}$ and $\mathrm{PbS}$ with $\mathrm{COO}^{-}$ and -SH respectively (shown in ESI†). According to the previous report, ${ }^{35}$ the composite peak at $1411 \mathrm{~cm}^{-1}$, rising from the combination or overlap of $\mathrm{O}-\mathrm{H}$ bending, the carboxyl carbon and aromatic carbon stretching, 19a (the Wilson notation) coupled with $\mathrm{COO}^{-}$asymmetric stretch, can be ascribed to b2 mode. Thus, due to the selective enhancement of b2 mode, the increased peak area at $1411 \mathrm{~cm}^{-1}$ is observed after the introduction of PbS NPs.

According to the CT model of Lombardi, ${ }^{21}$ only totally symmetric vibrational modes of the probe molecules are expected to be enhanced via the Franck-Condon contribution, and the Herzberg-Teller effect can enhance both totally and nontotally symmetric vibrational signatures in the SERS spectra of the probe molecules. That is, the b2 mode can be selectively enhanced by the CT mechanism through the Herzberg-Teller contribution. To further demonstrate the enhancement of b2 mode in the $\mathrm{TiO}_{2} / \mathrm{MBA} / \mathrm{PbS}$ system, the nonlinear Lorentzian curve fit of the SERS spectra was performed. In Fig. 5a, an enhancement of the b2 mode in SERS spectra of MBA molecules is observed in the fit result. For comparison, we also calculated the intensity ratio between the two modes at $1583 \mathrm{~cm}^{-1}(\mathrm{~b} 2)$ and $1075 \mathrm{~cm}^{-1}$ (a1) and plotted the column diagram (Fig. 5b). The band at $1075 \mathrm{~cm}^{-1}$ (C-S stretch, a1) was selected because it is intense and relatively isolated from interference. The fit result indicates that the b2 mode is enhanced selectively derived from the enhanced CT process that occurs after introducing PbS NPs into the $\mathrm{TiO}_{2} / \mathrm{MBA}$ system. As we know, the SERS signals in $\mathrm{TiO}_{2} /$ MBA have been attributed to the dominant contribution of the $\mathrm{TiO}_{2}$-to-molecule CT mechanism. ${ }^{22,34,36}$ Then, it can be deduced that the introduction of PbS NPs enhances the $\mathrm{TiO}_{2}$-to-molecule CT process. These results agree with previous reports of the SERS spectra of MBA. ${ }^{33}$ Additionally, Fig. S3 in the ESI $\uparrow$ shows the SERS spectrum of the PbS/MBA system, which further prove that the changes in SERS occur due to the interaction between $\mathrm{TiO}_{2} \mathrm{NPs}$ and PbS NPs.

It is also noteworthy that the interaction in $\mathrm{TiO}_{2} / \mathrm{MBA} / \mathrm{PbS}$ system also influences the phonon vibrational mode of $\mathrm{TiO}_{2}$ NPs. Fig. 6 shows the Raman spectra of $\mathrm{TiO}_{2}$ collected from $\mathrm{TiO}_{2} /$ $\mathrm{MBA}$ and $\mathrm{TiO}_{2} / \mathrm{MBA} / \mathrm{PbS}$ systems in the region of $100-700 \mathrm{~cm}^{-1}$. Raman modes at 145, 197, 398, 517 and $639 \mathrm{~cm}^{-1}$ are assigned as
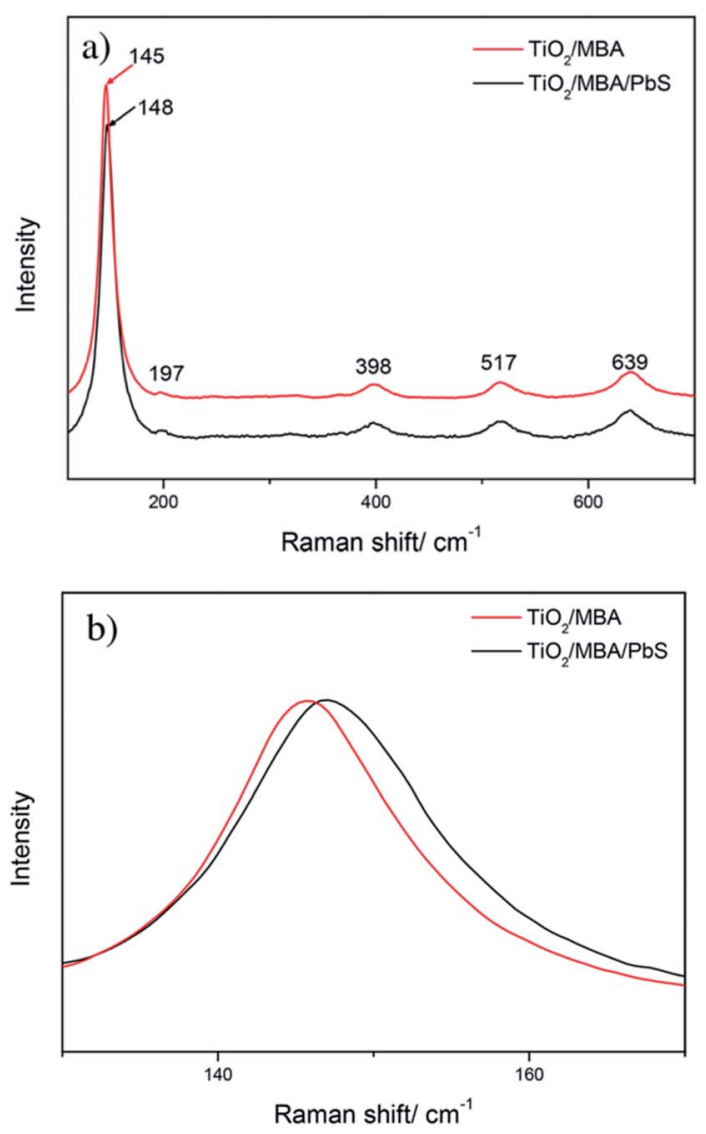

Fig. 6 (a) The Raman spectra of $\mathrm{TiO}_{2}$ collected from $\mathrm{TiO}_{2} / \mathrm{MBA}$ and $\mathrm{TiO}_{2} / \mathrm{MBA} / \mathrm{PbS}$ systems in the region of $100-700 \mathrm{~cm}^{-1}$ and (b) the enlarged SERS spectra between 130 and $170 \mathrm{~cm}^{-1}$. 
$\mathrm{Eg}$, Eg, B1g, A1g (or B1g), and Eg modes in anatase phase, respectively. ${ }^{37}$ For comparison, they are also normalized to the intensity of the $\mathrm{Eg}(1)$ peak $\left(145 \mathrm{~cm}^{-1}\right.$ in $\left.\mathrm{TiO}_{2} / \mathrm{MBA}\right)$. It can be observed that the peak at $145 \mathrm{~cm}^{-1}$ shifts toward higher wavenumbers and broadens after introducing $\mathrm{PbS}$ NPs into $\mathrm{TiO}_{2} / \mathrm{MBA}$ (Fig. 6b). As Fig. $4 \mathrm{~S} \dagger$ shows, the changes in $\mathrm{TiO}_{2} / \mathrm{MBA} / \mathrm{PbS}$ come from the interaction between $\mathrm{TiO}_{2}$ and $\mathrm{PbS}$, instead of MBA molecules. Thus, it can be deduced that the introduction of $\mathrm{PbS}$ NPs enhanced the CT process from $\mathrm{TiO}_{2}$ to MBA molecules, which further influences the phonon density of states in anatase $\mathrm{TiO}_{2}$. Then, the changes are reflected in the Raman spectra of $\mathrm{TiO}_{2}$ phonon vibrational mode. This phenomenon is similar to previous work where the light-induced transformations were observed due to the interaction between the $\mathrm{TiO}_{2}$ and $\mathrm{Au}$ NPs. ${ }^{38}$

\section{Analysis of the CT effect in the $\mathrm{TiO}_{2} / \mathrm{MBA} / \mathrm{PbS}$ system}

As Fig. 5 shows, the intensity of the SERS signal at $158 \mathrm{~cm}^{-1}$ (b2), driven by the enhancement of the $\mathrm{TiO}_{2}$-to-molecule CT process in $\mathrm{TiO}_{2} / \mathrm{MBA} / \mathrm{PbS}$ system, is obviously higher than that in the $\mathrm{TiO}_{2} / \mathrm{MBA}$ system. According to previous work, in $\mathrm{TiO}_{2} /$
MBA/Ag sandwich-structure system the stronger electrons attracting ability of $\mathrm{Ag}$ NPs promotes the $\mathrm{TiO}_{2}$-to-molecule CT process. In this work, it seems that the PbS NPs in $\mathrm{TiO}_{2} / \mathrm{MBA} /$ $\mathrm{PbS}$ system possibly play a similar role in the $\mathrm{TiO}_{2}$-tomolecule CT process. In previous work, ${ }^{23,39}$ efficient electron transfer from $\mathrm{PbS}$ QDs to $\mathrm{TiO}_{2}$ occurs only for QD diameters below approximately $4.3 \mathrm{~nm}$. However, as Fig. 2c shows, the diameter of PbS NPs in our system is about $70 \mathrm{~nm}$. And the work function of PbS NPs is $4.9 \mathrm{eV}$, which is higher than that of $\mathrm{TiO}_{2}$ NPs $(4.7 \mathrm{eV}) .^{\mathbf{4 0 4 1}}$ As the two kinds of materials with different work functions come in close contact with each other, the electrons are driven to transfer from one with lower work function to the other until equilibration of Fermi level. Therefore, when $\mathrm{TiO}_{2}$ NPs come into contact with PbS NPs in the $\mathrm{TiO}_{2} / \mathrm{MBA} / \mathrm{PbS}$ system, electrons tend to transit from $\mathrm{TiO}_{2}$ to $\mathrm{PbS}$, which is favorable to $\mathrm{TiO}_{2}$-to-molecule CT process. Then, the enhancement of b2-type vibrational mode is observed in SERS spectra (Fig. 5a). Similar phenomenon where the SERS spectra changes due to the interaction of two kinds of semiconductor NPs has been reported by Qian et al. previously. ${ }^{25}$ In their report, the SERS signal of bridge molecules show similar
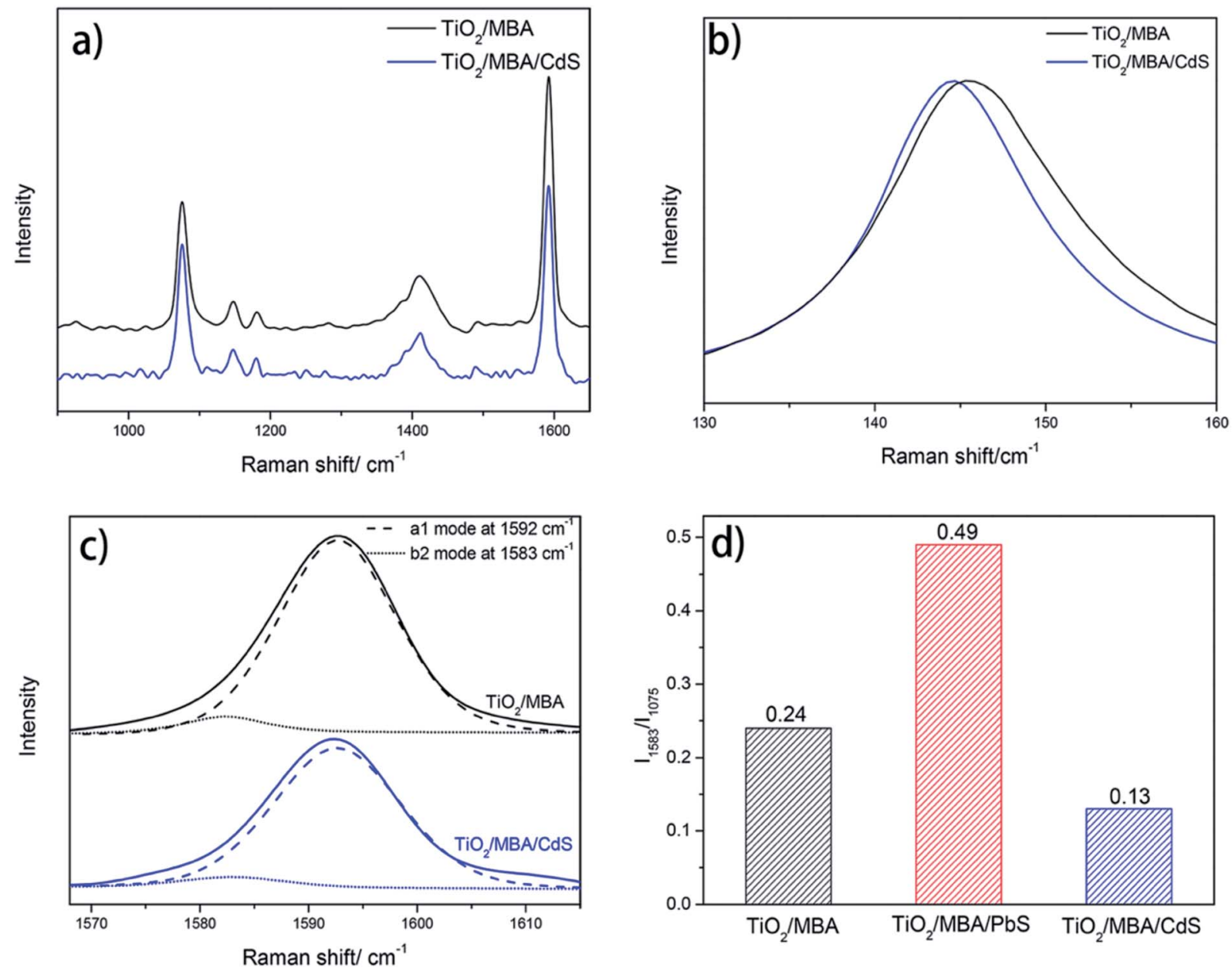

Fig. 7 (a) The SERS spectra of the $\mathrm{TiO}_{2} / \mathrm{MBA}$ and $\mathrm{TiO}_{2} / \mathrm{MBA} / \mathrm{CdS}$ systems at 633 excitation, and (b) the enlarged SERS spectra between 1560 and $1620 \mathrm{~cm}^{-1}$; (b) the enlarged SERS spectra between 130 and $170 \mathrm{~cm}^{-1}$; (c) the nonlinear Lorentzian curve fit of the SERS spectra in TiO $/ \mathrm{MBA}$ and $\mathrm{TiO}_{2} / \mathrm{MBA} / \mathrm{CdS}$ systems between 1568 and $1615 \mathrm{~cm}^{-1}$, and (d) the SERS intensity ratio between the modes at 1583 and $1075 \mathrm{~cm}^{-1}$ in the TiO $/$ $\mathrm{MBA}, \mathrm{TiO}_{2} / \mathrm{MBA} / \mathrm{PbS}$ and $\mathrm{TiO}_{2} / \mathrm{MBA} / \mathrm{CdS}$ systems. 
changes after introducing CdS NPs into the $\mathrm{TiO}_{2} / \mathrm{MPA}$ system. From the above discussion, it can be deduced that the interaction between the semiconductor NPs has an effect on the $\mathrm{TiO}_{2}$ to-molecule CT process. And the effect can be reflected in the SERS spectra where the CT-sensitive bands show enhancement under the interaction. Thus, the SERS model of the "donorbridge-acceptor" system may be applicable to investigate the interfacial CT effect between different materials.

\section{SERS spectra of the $\mathrm{TiO}_{2} / \mathrm{MBA} / \mathrm{CdS}$ system}

To further confirm the proposed mechanism, we also investigated the SERS spectra of the $\mathrm{TiO}_{2} / \mathrm{MBA} / \mathrm{CdS}$ system in Fig. 7. The XRD pattern and TEM of the $\mathrm{TiO}_{2} / \mathrm{MBA} / \mathrm{CdS}$ system are shown in Fig. S5. $\dagger$ The work function of CdS NPs is $4.5 \mathrm{eV}$, which is lower than that of $\mathrm{TiO}_{2}$ NPs $(4.7 \mathrm{eV}) .^{40,41}$ Therefore, when $\mathrm{TiO}_{2}$ NPs come in contact with CdS NPs in the $\mathrm{TiO}_{2} / \mathrm{MBA} /$ CdS system, electrons tend to transit from CdS NPs to $\mathrm{TiO}_{2}$, which is consistent with previous works. Then the $\mathrm{TiO}_{2}$-tomolecule CT process is inhibited. As we expect, the SERS spectra of the $\mathrm{TiO}_{2} / \mathrm{MBA} / \mathrm{CdS}$ system would show opposite changes compared with the $\mathrm{TiO}_{2} / \mathrm{MBA} / \mathrm{PbS}$ system. Fig. 7a shows the SERS spectra (excited at $633 \mathrm{~nm}$ ) of MBA molecules in the $\mathrm{TiO}_{2} / \mathrm{MBA}$ and $\mathrm{TiO}_{2} / \mathrm{MBA} / \mathrm{CdS}$ systems. For comparison, the
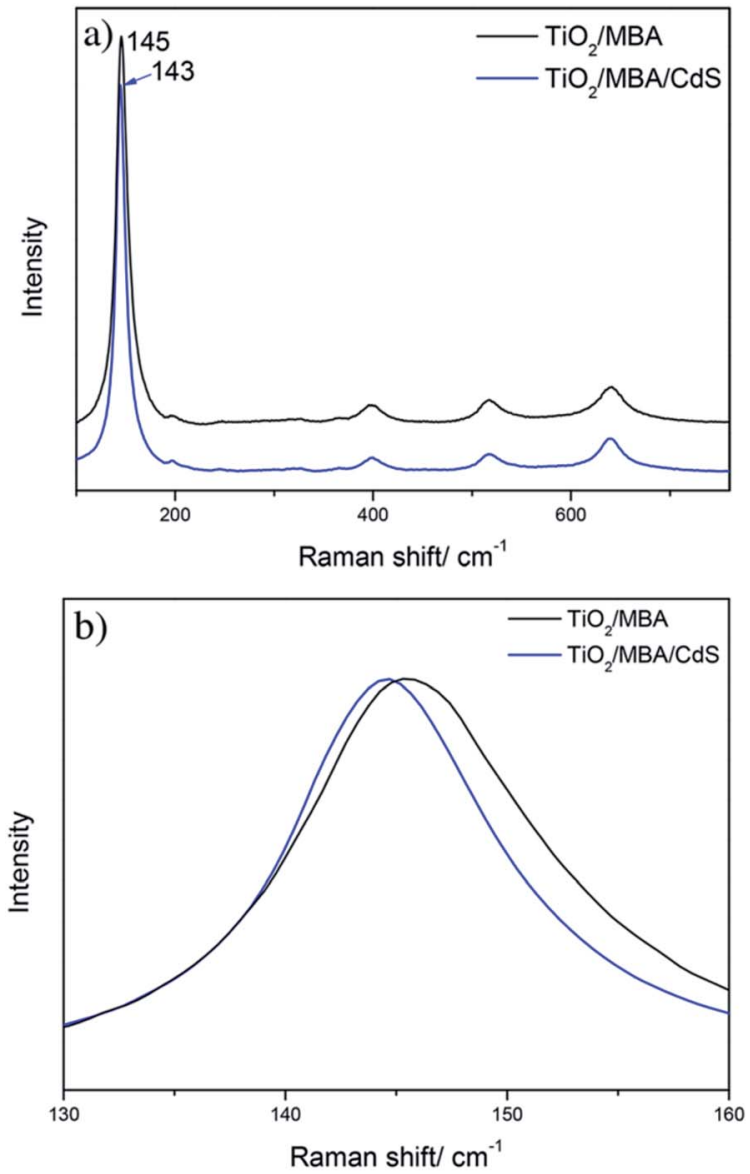

Fig. 8 (a) The Raman spectra of $\mathrm{TiO}_{2}$ collected from the $\mathrm{TiO}_{2} / \mathrm{MBA}$ and $\mathrm{TiO}_{2} / \mathrm{MBA} / \mathrm{CdS}$ systems, and (b) the enlarged SERS spectra between 130 and $160 \mathrm{~cm}^{-1}$.
Raman spectra were also normalized using the band at $1075 \mathrm{~cm}^{-1}$. After introducing CdS NPs, the band at $1583 \mathrm{~cm}^{-1}$ assigned to non-totally symmetric $\nu$ (CC) displays a decrease in the intensity of the SERS spectrum, while the band at $1592 \mathrm{~cm}^{-1}$ assigned to the aromatic $\nu$ (CC) mode shows no significate changes (Fig. 7c and d). The SERS spectrum of CdS/MBA is shown in Fig. S6† to exclude the interference from CdS/MBA.

Meanwhile, the Raman spectra of $\mathrm{TiO}_{2}$ collected in the $\mathrm{TiO}_{2} /$ MBA/CdS system also show opposite changes compared with the $\mathrm{TiO}_{2} / \mathrm{MBA} / \mathrm{PbS}$ system. As Fig. 8 shows, the peak at $145 \mathrm{~cm}^{-1}$ shifts toward lower wavenumber and becomes narrower after introducing CdS NPs into $\mathrm{TiO}_{2} / \mathrm{MBA}$, which is completely opposite to what we observed in the $\mathrm{TiO}_{2} / \mathrm{MBA} / \mathrm{PbS}$ system.

From above analysis, it can be deduced that the CT process between different semiconductor NPs has different effects on the $\mathrm{TiO}_{2}$-to-molecule CT process. And these effects on the $\mathrm{TiO}_{2}$-tomolecule CT process can be reflected in the SERS spectra where the CT-sensitive vibrational modes of probe molecules and the phonon vibrational mode of $\mathrm{TiO}_{2}$ show different changes. Thus, the CT process in coupled semiconductor nanoparticle systems can be investigated by applying the SERS method to a semiconductor-probe molecule-semiconductor physical model.

\section{Conclusions}

In this work, the $\mathrm{TiO}_{2} / \mathrm{MBA} / \mathrm{PbS}$ system has been fabricated as a model to study the interfacial CT effects in coupled semiconductor nanoparticle system with SERS technique. As compared with the SERS signal in the $\mathrm{TiO}_{2} / \mathrm{MBA}$ system, the SERS signals of MBA in the $\mathrm{TiO}_{2} / \mathrm{MBA} / \mathrm{PbS}$ system show distinct differences. The peak assigned to the b2 mode is significantly enhanced in the $\mathrm{TiO}_{2} / \mathrm{MBA} / \mathrm{PbS}$ system. Meanwhile, the Raman spectra of $\mathrm{TiO}_{2}$ phonon vibrational mode also exhibit obvious difference in Raman frequency. These phenomena can be ascribed to the interaction between the $\mathrm{TiO}_{2}$ and $\mathrm{PbS}$ NPs where the CT trend from $\mathrm{TiO}_{2}$ to molecules is enhanced because the Fermi level of $\mathrm{TiO}_{2}$ is higher than that of PbS NPs. To prove this point, we also investigated SERS spectra of the $\mathrm{TiO}_{2} / \mathrm{MBA} / \mathrm{CdS}$ system where the relative position of Fermi level is different from that of the $\mathrm{TiO}_{2} / \mathrm{MBA} / \mathrm{PbS}$ system. And the result is in good accordance with our proposed mechanism. Thus, we can conclude from this work that it is possible to investigate the CT process in coupled semiconductor nanoparticle systems with a semiconductor-bridge molecule-semiconductor physical SERS model. It is expected that this study will not only provide a deep investigation of the CT process in coupled semiconductor nanoparticle systems but also be valuable for practical application of SERS technology in the nanomaterial field.

\section{Conflicts of interest}

There are no conflicts to declare.

\section{Acknowledgements}

The research was supported by the National Natural Science Foundation (Grants. 21273091, 21221063, 21327803, 
21411140235, 21073072) of P. R. China; the 111 project (B06009); and the Development Program of the Science and Technology of Jilin Province (20110338, 20130305005GX).

\section{References}

1 Y. Bessekhouad, D. Robert and J. V. Weber, J. Photochem. Photobiol., A, 2004, 163, 569-580.

2 J. S. Im, S. K. Lee and Y.-S. Lee, Appl. Surf. Sci., 2011, 257, 2164-2169.

3 E. Ghadiri, B. Liu, J.-E. Moser, M. Grätzel and L. Etgar, Part. Part. Syst. Charact., 2015, 32, 483-488.

4 Z. He, W. Que, Y. Xing and X. Liu, J. Alloys Compd., 2016, 672, 481-488.

5 S. A. Mozaffari, M. Ranjbar, E. Kouhestanian, H. Salar Amoli and M. H. Armanmehr, Mater. Sci. Semicond. Process., 2015, 40, 285-292.

6 S. Sardar, P. Kar, S. Sarkar, P. Lemmens and S. K. Pal, Sol. Energy Mater. Sol. Cells, 2015, 134, 400-406.

7 M. Fleischmann, P. J. Hendra and A. J. McQuillan, Chem. Phys. Lett., 1974, 26, 163-166.

8 R. P. Li, J. L. Yang, J. H. Han, J. H. Liu and M. J. Huang, Phys. E, 2017, 88, 164-168.

9 C. Y. Zhang, R. Hao, B. Zhao, Y. Z. Fu, H. J. Zhang, S. Moeendarbari, C. S. Pickering, Y. W. Hao and Y. Q. Liu, Appl. Surf. Sci., 2017, 400, 49-56.

10 X. G. Zhang, Z. G. Dai, S. Y. Si, X. L. Zhang, W. Wu, H. B. Deng, F. B. Wang, X. H. Xiao and C. Z. Jiang, Small, 2017, 13, 1603347.

11 R. Berenguer, A. La Rosa-Toro, C. Quijada and E. Morallon, Appl. Catal., B, 2017, 207, 286-296.

12 C. C. Lin, C. Y. Lin, C. J. Kao and C. H. Hung, Sens. Actuators, $B, 2017,241,513-521$.

13 K. K. Reza, J. Wang, R. Vaidyanathan, S. Dey, Y. L. Wang and M. Trau, Small, 2017, 13, 1602902.

14 Y. Sun, L. Xu, F. D. Zhang, Z. G. Song, Y. W. Hu, Y. J. Ji, J. Y. Shen, B. Li, H. Z. Lu and H. F. Yang, Biosens. Bioelectron., 2017, 89, 906-912.

15 X. M. Li, M. H. Bi, L. Cui, Y. Z. Zhou, X. W. Du, S. Z. Qiao and J. Yang, Adv. Funct. Mater., 2017, 27, 1605703.

16 A. K. Pal and D. B. Mohan, J. Alloys Compd., 2017, 698, 460468.

17 S. G. Harroun, Y. T. Zhang, T. H. Chen, C. R. Ku and H. T. Chang, Spectrochim. Acta, Part A, 2017, 176, 1-7.

18 A. Campion and P. Kambhampati, Chem. Soc. Rev., 1998, 27, 241-250.

19 R. S. Das and Y. K. Agrawal, Vib. Spectrosc., 2011, 57, 163176.

20 E. J. Zeman and G. C. Schatz, J. Phys. Chem., 1987, 91, 634643.
21 J. R. Lombardi and R. L. Birke, J. Phys. Chem. C, 2008, 112, 5605-5617.

22 L. Yang, X. Jiang, W. Ruan, B. Zhao, W. Xu and J. R. Lombardi, J. Phys. Chem. C, 2008, 112, 20095-20098.

23 C. Ratanatawanate, C. Xiong and K. J. Balkus, ACS Nano, 2008, 2, 1682-1688.

24 Y. Sun, E. Hao, X. Zhang, B. Yang, M. Gao and J. Shen, Chem. Commun., 1996, 2381-2382, DOI: 10.1039/CC9960002381.

25 S. Qian, C. Wang, W. Liu, Y. Zhu, W. Yao and X. Lu, J. Mater. Chem., 2011, 21, 4945-4952.

26 X. Xue, W. Ji, Z. Mao, Z. Li, W. Ruan, B. Zhao and J. R. Lombardi, Spectrochim. Acta, Part A, 2012, 95, 213-217.

27 W. Choi, A. Termin and M. R. Hoffmann, J. Phys. Chem., 1994, 98, 13669-13679.

28 L. B. Liao, H. Y. Zhou and X. M. Xiao, Chem. Phys., 2005, 316, 164-170.

29 X. Xue, W. Ji, Z. Mao, H. Mao, Y. Wang, X. Wang, W. Ruan, B. Zhao and J. R. Lombardi, J. Phys. Chem. C, 2012, 116, 8792-8797.

30 L. Yang, X. Jiang, W. Ruan, J. Yang, B. Zhao, W. Xu and J. R. Lombardi, J. Phys. Chem. C, 2009, 113, 16226-16231.

31 P. Yin, R. U. I. Zhang, Y. Zhang and L. I. N. Guo, Int. J. Mod. Phys. B, 2010, 24, 3257-3262.

32 X. Zhang, Z. Yu, W. Ji, H. Sui, Q. Cong, X. Wang and B. Zhao, J. Phys. Chem. C, 2015, 119, 22439-22444.

33 Y. Wang, W. Ji, H. Sui, Y. Kitahama, W. Ruan, Y. Ozaki and B. Zhao, J. Phys. Chem. C, 2014, 118, 10191-10197.

34 X. Jiang, X. Li, X. Jia, G. Li, X. Wang, G. Wang, Z. Li, L. Yang and B. Zhao, J. Phys. Chem. C, 2012, 116, 14650-14655.

35 R. Li, H. Lv, X. Zhang, P. Liu, L. Chen, J. Cheng and B. Zhao, Spectrochim. Acta, Part A, 2015, 148, 369-374.

36 L. Yang, Y. Zhang, W. Ruan, B. Zhao, W. Xu and J. R. Lombardi, J. Raman Spectrosc., 2009, 721-726, DOI: 10.1002/jrs.2511.

37 S. Kelly, F. H. Pollak and M. Tomkiewicz, J. Phys. Chem. B, 1997, 101, 2730-2734.

38 O. L. Stroyuk, V. M. Dzhagan, A. V. Kozytskiy, A. Y. Breslavskiy, S. Y. Kuchmiy, A. Villabona and D. R. T. Zahn, Mater. Sci. Semicond. Process., 2015, 37, 3-8.

39 D. F. Wang, H. G. Zhao, N. Q. Wu, M. A. El Khakani and D. L. Ma, J. Phys. Chem. Lett., 2010, 1, 1030-1035.

40 K. P. Bhandari, P. J. Roland, H. Mahabaduge, N. O. Haugen, C. R. Grice, S. Jeong, T. Dykstra, J. Gao and R. J. Ellingson, Sol. Energy Mater. Sol. Cells, 2013, 117, 476-482.

41 A. R. Kumarasinghe, W. R. Flavell, A. G. Thomas, A. K. Mallick, D. Tsoutsou, C. Chatwin, S. Rayner, P. Kirkham, S. Warren, S. Patel, P. Christian, P. O'Brien, M. Gratzel and R. Hengerer, J. Chem. Phys., 2007, 127, 114703. 